\title{
IMAGINARIOS DE ESPACIO Y DE SUJETO \\ EN LA NARRATIVA ARGENTINA RECIENTE: \\ LAS GUERRAS, EL TRAUMA, EL NEOLIBERALISMO Y LA CULPA EN LAS ISLAS DE CARLOS GAMERRO*
}

\author{
IMAGINARY OF SPACE AND SUBJECT IN RECENT ARGENTINE \\ NARRATIVE: WARS, TRAUMA, NEOLIBERALISM AND GUILT \\ IN LAS ISLAS BY CARLOS GAMERRO
}

\author{
Macarena Areco \\ Pontificia Universidad Católica de Chile \\ mareco@uc.cl
}

\begin{abstract}
Resumen: En este ensayo analizo los imaginarios de espacio y de sujeto asociados a la guerra de Malvinas y al neoliberalismo en la novela Las Islas (1998) del escritor argentino Carlos Gamerro, entre ellos la torre de espejos del poder posmoderno, la experiencia de la subjetividad subalterna en el capitalismo tardío y la de la víctima atada por una culpa que no le pertenece. También estudio los trayectos de cooptación y de atrapamiento que se representan en el relato, así como los intentos de fuga y de emancipación, que culminan en un ambiguo cuento de hadas que da cuenta de lo irresoluble del problema propuesto en la narración.
\end{abstract}

Palabras clave: Imaginario social, espacio, sujeto, narrativa argentina reciente, Malvinas, dictadura y posdictadura.

\begin{abstract}
In this paper I analyze the imaginary of space and subject associated with the Falklands war and neoliberalism in the novel Las Islas (1998) by Argentine writer Carlos Gamerro, including the tower of mirrors of postmodern power, the experience of subaltern subjectivity in late capitalism and the victim's being tied by guilt that does not belong to him. I also study the routes of cooptation and entrapment that are represented in the story and attempts of escape and emancipation, culminating in an ambiguous fairytale that evidences how intractable the problem proposed in the narrative is.
\end{abstract}

Keywords: Social imaginary, spaces, subjectivity, Argentine recent narrative, Falklands, dictatorship, post-dictatorship.

Recibido: 03.02.2015. Aceptado: 03.07.2015.

* Este artículo ha sido escrito en el marco del proyecto Fondecyt 1130489. 
$\mathrm{C}$ ON UNA NARRACIÓN HÍBRIDA, que imbrica una trama policial básica de asesinato e investigación con elementos de ciberpunk, cuento de hadas, ficcionalización de la historia, leyenda, pastiche, sátira y parodia, entre otras modalidades de relato, el argentino Carlos Gamerro construye en Las Islas (2012 [1998]) una de las novelas más significativas del periodo de la posdictadura en el Cono Sur, en que relata el doble trauma que afecta a su generación y a su país: las dos guerras de los últimos años, la de los setenta y la de los ochenta: la guerra sucia y la de Las Malvinas. Éstas se narran a través de una subjetividad dañada, la de un ex combatiente convertido en hacker, Felipe Félix, antihéroe característico del ciberpunk, a una década exacta del conflicto armado, en junio de 1992, en la Argentina del menemismo que representa la plena vigencia del capitalismo globalizado. En este escenario el autor constituye un complejo entramado de figuraciones imaginarias de espacio, sujeto y trayecto surgidas de esta situación traumática y de sus vínculos con el neoliberalismo ${ }^{1}$, al modo de un mapa cognitivo (Jameson) que visibiliza los reflejos y los traumas del presente y de este modo intenta comprenderlos y superarlos.

Carlos Gamerro nació en 1962, de modo que pertenece a la generación de quienes fueron enviados a combatir en el extremo sur, pero, por encontrarse en México, no fue reclutado ${ }^{2}$. Su obra abarca la narrativa, la traducción, el guión y el ensayo. En este último género ha escrito Harold Bloom y el canon literario (2003), El nacimiento de la literatura argentina y otros ensayos (2006), Ulises. Claves de lectura (2008) y Ficciones barrocas. Una lectura de Borges, Bioy Casares, Silvina Ocampo, Cortázar, Onetti y Felisberto Hernández (2010). Este último puede ser una de las claves de lectura de su narrativa, que tiene como centro su primera novela Las Islas,

${ }^{1}$ En una entrevista del suplemento Radar de Página/12, Gamerro establece un claro vínculo entre ambas: "La dictadura militar y el menemismo son espejos uno del otro, dos procesos que no pueden entenderse uno sin el otro". "El eterno retorno" (24 de abril de 2011).

2 "Soy clase '62, la clase que fue a Malvinas. No fui a Malvinas. Malvinas, en ese sentido, me dejó la sensación de una vida, quizá también una muerte, paralela, fantasmal (la mía, si me hubiera tocado ir a la guerra). La ficción no sólo existe en la literatura, existe en cada uno de nosotros, en esas otras vidas posibles que se desarrollan paralelamente a la que nos tocó, o elegimos. Ese fue mi segundo descubrimiento: que la literatura puede ser autobiográfica en negativo: la historia no de lo que nos pasó sino de lo que nos pudo haber pasado”. Radar de Página/12 (11 de abril de 2010). 
una obra barroca en torno a la cual Gamerro ha constituido una especie de saga. Así, por una parte, en El sueño del señor juez (2000), que la sigue, se relatan los orígenes genocidas en el siglo XIX del poblado que había aparecido en la narración sobre Las Malvinas como una suerte de espacio idílico de la infancia, Malihuel, mientras que en El secreto y las voces (2011 [2002]), su tercera novela, se narra la investigación que realiza en ese lugar Fefe, que en realidad es Felipe Félix, del asesinato y desaparición de un joven del pueblo, en los inicios de la dictadura. Por la otra, en La aventura de los bustos de Eva (2012 [2004]) y Un yuppie en la columna del Che Guevara (2011) se trata de las peripecias de un personaje episódico de la novela central, el ejecutivo Ernesto Marroné, encargado de conseguir 92 bustos de Eva Perón para salvar a su jefe, el mefistofélico empresario nazi de Las Islas Fausto Tamerlán, que los guerrilleros que lo tienen secuestrado hace seis meses exigen dentro del rescate. Como ocurre en la obra de Gabriel García Márquez, gran parte de lo escrito por Gamerro aclara episodios del mundo imaginado previamente en Las Islas, al cual sólo los cuentos de El libro de los afectos raros (2013 [2005]) no hacen referencia.

\section{La mosca en los cristales engañosos}

Las Islas es la historia de Felipe Félix, un ex combatiente en Las Malvinas, una especie de muerto en vida ${ }^{3}$ que todavía lleva incrustado en la cabeza como estigma un pedazo de casco y que sobrevive realizando algunos trabajos como hacker, por lo cual es contratado por el millonario de origen alemán Fausto Tamberlán, justo a diez años del conflicto, para ubicar a los testigos del asesinato cometido por su hijo César, quien ha despeñado desde una de sus dos torres de espejos, que es la sede de sus empresas, a un desconocido. En su pesquisa Felipe se entrevista con diversos personajes, entre ellos los veteranos cuyas vidas giran en torno a las islas, los jefes

${ }^{3}$ En Los prisioneros de la torre, Elsa Drucaroff ha analizado en la narrativa de posdictadura la "mancha temática de 'jóvenes que viven como muertos'... muchachos y chicas que, aunque están vivos, deambulan como fantasmas, personajes dolorosamente vaciados por una Historia que no ha sabido tejer para ellos continuidad y transmisión" (2011, p. 123). 
nacionalistas de éstos, Gloria, quien fue detenida ilegalmente durante la dictadura y torturada y violada por un militar, con quien posteriormente se casó, las pequeñas hijas de ambos, Malvina y Soledad, con síndrome de Down, y Arturo Cuervo, el padre de las niñas, también héroe de guerra y autor de un misterioso diario, conocido como el Mayor X. En el final de la novela se descubre que el asesinado es el hijo mayor de Tamerlán, montonero y ex combatiente, y el millonario es asesinado por sus guardaespaldas que ahora sirven a César, quien hereda la compañía.

El universo barroco de Las Islas ${ }^{4}$ se basa en la parodia de los discursos ideológicos hegemónicos del siglo XX -el nacionalismo, el antisemitismo, el falologocentrismo y el neoliberalismo ${ }^{5}-\mathrm{y}$ en la expresión de complejas y proliferantes figuraciones del imaginario social ${ }^{6}$. Siguiendo el orden de la diégesis, lo que aparece en primera instancia son las figuraciones neoliberales del espacio, en particular la arquitectura posmodernista que le es característica, así como la experiencia de la subjetividad en estos lugares, en cuanto a sus posibilidades de movimiento y agencia. Luego el relato se remonta a las dos décadas anteriores para dar cuenta de las figuraciones nacionalistas, fascistas y patriarcales, deteniéndose en especial en la guerra de Las Malvinas, como episodio ejemplar de la violencia política y económica, y en el terrorismo de Estado, y dentro de él del filicidio7.

${ }^{4}$ En tanto la novela es una expresión del barroco temático que Gamerro ha caracterizado en relación con la obra de Borges, Bioy, Silvina Ocampo, Cortázar, Onetti y Felisberto Hernández en su ya mencionado ensayo sobre el barroco, en el que lo entiende como puesta en cuestión de la realidad de lo real a partir de la proliferación de representaciones (dobles, espejos, bifurcaciones, etc.).

${ }^{5}$ Gamerro ha dicho que "la novela trabaja sobre los discursos, no sobre la guerra" (http://asesinostimidos.blogspot.com/2008/o8/entrevista-carlos-gamerro.html).

${ }^{6}$ Castoriadis ha desarrollado la conceptualización del imaginario social en que se basa esta investigación, en su texto central, La institución imaginaria de la sociedad (2007 [1975]) y en diversos escritos posteriores que se detienen en cuestiones específicas. Entre ellos, en Figuras de lo pensable aclara el concepto de imaginario radical (social) y el de imaginación (individual): "En la historia, desde el origen, constatamos la emergencia de lo nuevo radical, y si no podemos recurrir a factores trascendentes para dar cuenta de eso, tenemos que postular necesariamente un poder de creación, una vis formandi, inmanente tanto a las colectividades humanas como a los seres humanos singulares. Por lo tanto, resulta absolutamente natural llamar a esta facultad de innovación radical, de creación y de formación, imaginario e imaginación” (1999: 93).

${ }^{7}$ Es éste una "mancha temática" que aparece de manera recurrente en la narrativa de la posdictadura, según el análisis que desarrolla Elsa Drucaroff (2011, pp. 331370 ). 
Respecto a lo primero, el narrador se detiene en describir las edificaciones de espejos del poder posmoderno:

las torres gemelas de Tamerlán emergiendo altas, limpias y cristalinas, como montañas de hielo, en un montaje tan incongruente que parecía generado por computadora. Las había visto innumerables veces, como todos los habitantes de la ciudad, pero siempre era como la primera, y necesitaba varios minutos para aceptar que realmente estaban allí: menos irreales en el recuerdo que frente a frente $(13)^{8}$.

Y un poco más adelante: "dos navajas alineadas filo contra filo que dejaban entre ellas un espacio intolerablemente delgado y perfecto a través del cual el rebote del sol sobre la plancha incandescente del río irrumpía con una violencia cegadora, casi sobrenatural” (14). Se recordará que Jameson describe el posmodernismo, que él entiende como la lógica cultural del tercer estadio del capitalismo, por ciertos rasgos: superficialidad, pastiche (surgido del descentramiento del sujeto y el fin del estilo), debilitamiento de la historicidad, esquizofrenia y fragmentación e intensidades, como nuevo sustrato emocional. Pero aquí me interesa mostrar, más que la presencia de esta estética en la novela de Gamerro, cómo en ella se representan las imaginaciones posmodernas. Para ello también sigo a Jameson, quien se sirve del concepto kantiano de lo sublime, entendido como lo físicamente inconmensurable y además como lo irrepresentable para el ser humano que se asocia a la naturaleza, para dar cuenta de la red informática de poder y control descentralizado del capitalismo avanzado, la cual es representada por el ciberpunk - uno de los géneros hibridizados en Las Islas- o los edificios de vidrio que con sus reflejos fragmentados y distorsionados expresan el papel central del procesamiento y la reproducción en la cultura actual. Las torres de cristal de Tamerlán -descritas como limpias, irreales,

\footnotetext{
${ }^{8}$ Como se ve en lo que sigue, las torres reemplazan a las representaciones menos eficaces anteriores: "como si sólo la imaginación pudiera concebir que la extensión de aguas barrosas del Río de la Plata hubiera cristalizado en estos dos palacios de hielo sin mancha, se habían convertido para todos los porteños en un nuevo símbolo de su ciudad, rivalizando incluso con el obelisco, insípido y primitivo en comparación. Para una ciudad que en más de cuatrocientos años no ha conseguido sobreponerse a la opresiva horizontalidad de pampa y río cualquier elevación considerable adquiere un carácter un poco sagrado, un punto de apoyo contra la gravedad aplastante de las dos llanuras interminables y el cielo enorme que pesa sobre ellas" (13).
} 
sagradas, cegadoras y sobrenaturales- expresan este sublime que tras la tecnología vela el poder 9 .

¿Cuál es la experiencia humana en un espacio de este tipo? Veamos lo que le ocurre a Felipe Félix la primera vez que visita las torres: "estaba tan mareado por los reflejos", dice y, más adelante, "[e]ra peor de lo que me esperaba. Había espejos en las paredes, espejos en el techo, espejos en el piso, espejos en los espejos. En rigor, decir en resulta inexacto: no había ni paredes ni techo ni suelo fuera de los espejos, no había sino espejos, y yo flotaba embebido en ellos como si la ley de gravedad y los puntos cardinales hubieran sido de pronto anulados" (14). Mareo, incapacidad de ubicarse: es la misma experiencia que se produce en el vestíbulo del Bonaventura según Jameson, donde el visitante experimenta "una confusión demoledora", pues a causa de "la simetría absoluta de las cuatro torres es casi imposible orientarse" (96). Se pierde así todo sentido de los volúmenes y las distancias:

el espacio nos impide utilizar el lenguaje del volumen tanto como los propios volúmenes, puesto que ya es imposible calcularlos, por todas partes ondean insignias que se dispersan por este espacio vacío para liberarlo... de cualquier forma que pudiéramos suponerle; y el constante trajín da la impresión de que se ha colmado totalmente el vacio, de que se está inmerso en ese elemento, sin ninguna de las distancias que en otros tiempos hacían posible percibir perspectivas o volúmenes. Se está de lleno en este hiperespacio, con el cuerpo y con los ojos (94-5).

Como dice Felipe, sin gravedad ni puntos cardinales, "en un florecimiento de reflejos que casi impedía caminar" (14); "[a]penas me atreví a

${ }_{9}^{9}$ Jameson analiza el edificio Bonaventura, construido en Los Angeles en 1977 por John Portman, el cual con sus paredes de espejos reflectantes expresa su voluntad de rechazo de la ciudad, en oposición a "la transformación política utópica" (1991 [1984]: 92) que se proponía el modernismo; la fachada de vidrio reflectante "repele hacia fuera la ciudad; una repulsión análoga a la de esas gafas de sol especulares que hacen imposible al interlocutor ver los ojos del que habla y que, por tanto, comportan una cierta agresividad hacia el Otro y un cierto poder sobre él. De forma parecida, la fachada de vidrio produce una disociación peculiar e ilocalizable del Bonaventura con respecto a su vecindario. . . cuando se intentan ver los muros externos del edificio, no se puede ver el hotel como tal, sino tan sólo las imágenes distorsionadas de todo lo que le rodea" (92). Las dos torres de Tamerlán, con su "incongruencia”, también niegan a la ciudad a la que no quieren salvar. 
dar unos pasos, me encontraba convertido en una especie de pólipo entreverado y proliferante" (14).

Antes, en el primer párrafo de la novela, ha aparecido una primera descripción de la experiencia de la subjetividad subalterna en el capitalismo tardío, comparada a la de un insecto atrapado en una tela de araña que disfruta de la libertad aparente, previa a la llegada de su depredador:

Una mosca, recién atrapada en una tela de araña, mientras la araña, repleta de haber comido, tarda en llegar, puede pasarla bastante bien si se relaja mientras espera. Los hilos son de una suavidad casi intangible, acompañan sin trabar cada movimiento del cuerpo, mientras no sea muy brusco. Es como estar tirado en una hamaca, en vacaciones, sin otra cosa que hacer que mecerse en la brisa y mirar el azul del cielo con los ojos entrecerrados. Sí, sí, podría quedarme toda la vida así tirado. Y si no me muevo demasiado estos hilos ni se sienten, son tan tenues, es como si flotara de espaldas en el aire. Sí, sólo se hacen reales cuando trato de zafarme (11).

Una vez en la torre, Felipe es conducido por el edificio: “-No te preocupes por el camino. Las paredes te lo van a señalar” (16), le advierte quien lo recibe, y es efectivamente lo que ocurre: "A medida que avanzaba por el pasillo las paredes se volvían a entrelazar a mis espaldas, por lo que no tenía más remedio que seguir adelante" $(16-7)^{10}$. No obstante, Felipe puede ver que la torre de Tamerlán, tras una aparente transparencia y falta de orden, esconde una jerarquía de hierro de control y vigilancia:

En el camino pasaron ante mis ojos los sucesivos estamentos de la colmena de vidrio, y noté con asombro que la torre se ordenaba hacia abajo a medida que subíamos, la confusión demencial de los espejos dando lugar al orden geométrico del vidrio traslúcido, y enseguida me di cuenta de por qué: el techo espejado de cada nivel se volvía el piso transparente del superior $(16)^{11}$.

${ }^{10}$ La narración continúa entregando indicios de la real situación del personaje en su recorrido por la torre, como sujeto subalterno a merced del poder: "Desemboqué en un vestíbulo donde la agresión de los espejos era moderada por espesos tapices del Renacimiento en los cuales, como cuadritos de historieta, un ciervo era sucesivamente sorprendido, perseguido, alcanzado y se debatía mordido por perros y atravesado por las flechas de los cazadores, agonizando en varios tonos de seda descolorida" (16-7).

${ }^{11}$ Felipe, como muerto en vida, se encuentra en una posición marginal, de ahí que 
En su primera conversación, Tamerlán le explica el simple mecanismo detrás de esta aparente complejidad:

-Son todos espejos - comenté, no hay paredes opacas.

-Reflectivos - me ayudó-. Vidrios transparentes para los jefes...

-Y espejos para los subordinados, concluí-. Ingenioso (33).

La torre de cristal es en realidad una "colmena de vidrio" (16) o un panóptico ("la vista del jefe llega a todas partes" (33)), y Tamerlán, el "señor de los espejos" (34), en el Macondo posmoderno que es el Buenos Aires de Las Islas. Pero el poder que ha construido esta confusión barroca de espejos y reflejos es demasiado nítido y César, que se ha dado cuenta de esta vulnerabilidad, explica cómo esto cambiará: "El control pasa a una sociedad anónima, y Canal yo quedamos apenas como accionistas. Ya acordamos la reestructuración. Vamos a rotar todos los espejos, para que nadie sepa muy bien donde está el jefe. Va a ser una democracia. Una democracia sin pueblo. Esa cosa personalista y jerárquica es muy vulnerable. El error de la araña" (153).

\section{El laberinto de Malvinas}

Los jóvenes clase 62, sobre los cuales también escribió Fogwill en Los Pichiciegos, que en 1983 fueron enviados a una guerra nacionalista que pretendía velar con el fervor patriótico los problemas internos de la dictadura,

en la torre del poder perciba su extrañeza, igual que el convaleciente hombre de la multitud de Poe: "Envuelto por un torbellino de movimiento, como el único avanzando en cámara lenta a través de una filmación en cámara rápida, crucé las trayectorias de hombres y mujeres que como balas trazadoras corrían de un lado al otro, entraban y salían por puertas invisibles, convergían velozmente sobre sus formas reflejadas, y a último momento, en lugar de estrellarse, se fundían con ellas y desaparecían. Al cruzarse se saludaban en un complejo ritual de insectos sociales, girando unos sobre otros en complicada figuras de baile, sacándose los anteojos espejados que la mayoría usaba. ...Parecía haber cientos, aunque era difícil decidir si se trataba de tantas personas o simplemente de la imagen de unas pocas repetida hasta el infinito en los cristales engañosos" (15). Entre la multitud, los anteojos del guardia que espera a Felipe "parecían dos escamas desprendidas de la torre y pegadas a sus ojos" (15). Como partes del sistema, los sujetos se mimetizan con la torre del poder posmoderna. 
la cual fue acogida con entusiasmo por gran parte de la población ${ }^{12}$, fueron víctimas del filicidio, una de las imaginaciones que, según Drucaroff, se configuran de manera recurrente en la narrativa de la posdictadura y en Las Islas. Pero en la novela, antes que el horror, Malvinas son el objeto perdido del deseo, que los veteranos sobrevivientes intentan recuperar realizando las más variadas copias: la maqueta que hace Ignacio y que no logra terminar pues intenta igualar en todos sus detalles al original; el juego de video que crea Felipe Félix donde los argentinos son tomados de imágenes de la guerra de Irak ${ }^{13}$; el tatuaje de Tomás, quien, herido en el brazo, "alrededor de las dos cicatrices estrelladas se había hecho tatuar el contorno de Las Islas" (61) ${ }^{14}$; o el caso más patético de Hugo, quien perdió las piernas, cuyos treinta años son celebrados con una torta de cumpleaños en la que "sostenidas sobre una escarpada ladera de merengue y rodeadas de un mar de grandeza azul, Las Islas resplandecían cubiertas de granza verde” (347). Definitivamente grotesca es la alegoría nacional creada por Citatorio, de la Asociación Virreinal Argentina ${ }^{15}$, quien imparte cursos a los ex combatientes, según la cual:

La Argentina es una pija parada lista para procrear, y las Malvinas son sus pelotas. iCuándo las recuperemos volverá la fertilidad a nuestras tierras, y seremos una gran nación como soñaron nuestros próceres!.. Buenos Aires se convertirá en la Nueva París, envidia de las ciudades

\footnotetext{
12 "Cuando se produce la toma de Malvinas yo estaba en una playa mejicana, y me entero una semana más tarde, mientras compraba una remera, por la radio del local. Regresé a la Argentina más o menos a principios de mayo, con la visión de los hechos que se tenía en el extranjero. Al llegar, la sensación principal fue de shock. Me parecía que todos estaban a favor de la guerra. Creí que todos se habían vuelto locos. O que yo estaba loco" (http://www.no-retornable.com.ar/v2/dossier/gamerro.html).

${ }_{13}$ "Elegí la Primera Guerra para los combates terrestres. ...Elegí un paisaje del frente ruso en el 44, no había tanta nieve y el terreno zafaba bastante bien, pero los soldados estaban demasiado abrigados para hacer de argentinos. Los caribeños en cambio se me pasaban de veraniegos. ...Busqué y busqué pero al final no encontré nada mejor que los iraquíes: con su facha morocha y sus uniformes de media estación pasaban lo más bien" (87).

${ }_{14}$ "Estaba tan orgulloso de su obra que usaba remera de manga corta hasta en invierno (¿Frío? ¿Me pregunta si siento frío? Yo le voy a contar lo que es el verdadero frío. Dos meses pasamos en las trincheras...” (61).

${ }^{15}$ Cuyo objetivo es "restaurar las fronteras nacionales a los límites históricos del Virreinato de la Plata (para lo cual propone, entre otras cosas, reconquistar Bolivia, Paraguay, Uruguay e invadir Chile y Brasil)" (52).
} 
del orbe. Una nueva Atenas... iEl argentino nombre de los argentinos repicará prístino en los oídos del mundo con sones de progreso y rique$\mathrm{za}$ ! (58-9).

Las islas de Gamerro son como los hrönir de Borges, copias de copias de copias de un original que nunca ha existido con los oropeles que el nacionalismo le presta. Pero Las Malvinas son también un laberinto, en el cual los veteranos sobrevivientes no hacen sino dar vueltas, como en el dibujo de Escher, que es descrito por Felipe:

muestra un grupo de hombres [que] parecen soldados antiguos, recorriendo una escalera que da la vuelta completa y termina donde empezó: los que suben terminan abajo, y los que bajan arriba. La escalera no tiene fin: cuantos más peldaños el soldado sube, más baja, y al revés: si se cansa y quiere retroceder es igual. Y sin embargo, todos siguen caminando, esperando que si persisten alguna vez llegarán al último peldaño. A las Islas sólo se llega por esa escalera, y con los años uno se va cansando (414).

Se trata del trauma de la guerra ${ }^{16}$, que ha convertido a los jóvenes clase 62 en vivos que viven como muertos, que habitan el laberinto sin salida de las Malvinas, para quienes el tiempo se ha congelado, como le ocurre a Felipe: "Diez años había dormido bajo el abrigo de la ciudad del dolor, y ahora despertaba desnudo bajo el brillo único de las estrellas" (554). Pero el despertar llega, y se produce cuando el hacker, después de ser torturado por el psicoanalista de los Tarmelán y ex montonero, Canal, con una droga

${ }^{16} \mathrm{El}$ trauma es una problemática ampliamente abordada por el psicoanálisis. Laplanche y Pontalis proponen en su diccionario una definición inicial que incluye los sentidos generales que consideramos para el análisis de la novela de Gamerro: "Acontecimiento de la vida del sujeto caracterizado por su intensidad, la incapacidad del sujeto de responder a él adecuadamente y el trastorno y los efectos patógenos duraderos que provoca en la organización psíquica" (1994, p. 447). Específicamente en relación con el trauma de guerra, Benjamin se refirió en El narrador a la situación de los soldados que regresaban después del conflicto de 1914: "Con la Guerra Mundial comenzó a hacerse evidente un proceso que desde entonces no ha llegado a detenerse. ¿No se advirtió que la gente volvía enmudecida del campo de batalla?” (2008, p. 60). Por su parte Agamben, a partir del testimonio de Primo Levi, ha afirmado que "[el]l sentimiento de culpa del superviviente es un locus classicus de la literatura sobre los campos" (2000, p. 93), lo cual, como veremos, es fundamental en el caso de Felipe Félix. 
del dolor, camina por la ciudad y se encuentra con sus compañeros de patrulla de las Malvinas, entre los cuales él es el único sobreviviente:

-¿Seguís odiándome? -le pregunté.

-¿Y desde cuando te odio yo? -me contesto...

-Desde ese día en que lo deje a Verraco hacerte... Desde esa noche en que me dormí mientras te morías al lado mío...

-Tu silencio suena a asentimiento -le dije con alivio...

-Estoy pensando en cómo explicarte, dijo quebrándolo.

-Qué.

-Que allá no nos importan esas cosas...

-Está bien lo admito, marcho preso. Tienen razón en venir a reclamarme. Yo mismo me declaro culpable, así ganamos tiempo...

-Escucháme, porteño, ¿vos sabés lo que es el infierno?

-Sí -asentí vehemente-. No te quepa duda. Puedo escribirte un libro.

-El nuestro es distinto. De lo que sufrimos en vida nos desnudamos para cruzar nadando al otro lado. Lo que recordamos lo recordamos sin dolor. Pero hay uno que cruza con nosotros. El de ustedes. El de los que siguen vivos...

-Lo único que les pedimos es que a veces nos dejen pasar. Pero con vos no había caso...

-No me atrevía a mirarlos a los ojos, tenía miedo -dije...

-¿De qué?

-De que me acusaran por haberlos olvidado...

-¿Olvidarnos?, ¿vos? Hace diez años que nos llevás cargados a la espalda -dijo Carlitos.

-Por no seguir la lucha -insistí tozudo. Porque estoy vivo y ustedes no. Porque en el fondo me pone contento. -Ya está, lo dije, pensé. Que ahora caiga de una vez el rayo y me fulmine.

-Todos estos años, estuvimos esperando para decírtelo -empezó amenazante Carlitos.

-Qué...

-Que no sientas culpa. Son ellos los que tienen la culpa. Los que nos pusieron a todos en esa situación. Son ellos los hijos de puta. Vos no, vos hiciste lo que pudiste (587-91).

Este encuentro con sus amigos fantasmas nos da la clave de que es la culpa lo que mantiene a Félix como un muerto en vida, al mismo tiempo que opera un reparto de las responsabilidades heterodoxo respecto al que se ha hecho en el imaginario de la posdictadura, en el que se ha interroga- 
do como principales culpables a sujetos subalternos (conscriptos, como en este caso, mujeres que se pasaron al bando enemigo, jóvenes militantes), mientras los grandes responsables defienden el terrorismo de Estado como servicio a la patria. Contra este imaginario oficial, la novela construye esta escena de reconocimiento, del otro y de sí mismo, en la cual se visibiliza a los verdaderos culpables ${ }^{17}$.

En la novela hay otros dos episodios que funcionan en el mismo sentido. El primero es el encuentro con Gloria, la mujer torturada por Cuervo, cuya piel, maravillosa en la oscuridad -"Esta piel, esta piel tan linda, repetía una voz adentro mío mientras refregaba en ella la nariz, los ojos, la boca, como en una toalla secada al sol al salir del mar" (301)- está cubierta de marcas: "Eran estas pequeñas cicatrices brillosas las que mis dedos habían detectado antes en la oscuridad, confundiéndolas con una ilusión táctil fruto de mi embeleso; el mapa que yo había trazado uniendo estos puntos con mis dedos recién ahora empezaba a tomar forma" (307). El encuentro con Gloria le permite a Felipe dimensionar el tamaño de la culpa de los torturadores: "se lo hicieron a esta piel, sentí en la garganta, en los ojos; fueron capaces de hacérselo a esta piel" (307). También hace posible poner en contacto y en común los estigmas; las heridas corporales se retroalimentan y de este modo se libera una parte de su carga. Pero no se trata solo del cuerpo, sino también del lenguaje, que recupera su función comunitaria y comunicativa: "las palabras, de repente, no servían sólo para quitarle cosas a alguien, o para imponérselas. Se prestaban, se regalaban, se acariciaban como un gato, se devolvían, se saboreaban en la boca, bajaban a veces hasta el pecho" (292).

El segundo es la desterritorialización del cuerpo de Felipe en la ciudad: "Perdiéndose en la visión el cielo, mi cuerpo empezó a esparcirse, como una gota de aceite sobre una superficie de agua. Mi piel se entendía hacia el horizonte, y. . . empezó a erizarse de edificios, casas, árboles, autos personas; me recorrían vías de ferrocarril en largas cicatrices cosidas..." (554). Esta proyección le permite al personaje salir simbólicamente de los espacios cerrados de su departamento, de las oficinas de la Asociación Virreinal Argentina y del Servicio de Inteligencia del Ejército, SIDE (que funciona

${ }^{17}$ En el artículo sobre confesiones que incluyo en la bibliografía profundizo en esto (2014, pp. 69-82). 
en el subterráneo de un shopping center), y del fetiche espacial que son las islas -epítome de lo cerrado-, como asimismo de los discursos autosuficientes, incomunicables e incomunicados entre sí y con la realidad que perdieron como referente, es decir, del laberinto.

De este modo, lo que describe Las Islas es el trayecto de atrapamiento, en la memoria traumática que afecta al protagonista, que se propone como un laberinto, del cual, no obstante, se puede salir, gracias al encuentro con los jóvenes fantasmas y con Gloria ${ }^{18}$. No se puede afirmar lo mismo respecto a la caída de Felipe en la tela de araña del poder neoliberal, que sigue operando bajo las nuevas formas, como ha explicado el heredero de Tamerlán, pero también aquí se ha producido un reconocimiento, en el sentido que establece el anticuento de hadas que Gloria relata al final, sobre una princesa que se casa con un sapo y que empieza a convertirse en uno de ellos, que se comprende gracias al epígrafe de Calvino:

El infierno de los vivos no es algo que será; hay uno, es aquel que existe ya aquí, el infierno que habitamos todos los días, que formamos estando juntos. Dos maneras hay de no sufrirlo. La primera es fácil para muchos: aceptar el infierno y volverse parte de él hasta el punto de no verlo más. La segunda es peligrosa y exige atención y aprendizaje continuos: buscar y saber reconocer quién y qué, en medio del infierno, no es infierno, y hacer que dure, y darle espacio.

El recurso a lo fantástico, a los fantasmas y al cuento de hadas, me parece que da cuenta de la enorme dificultad de la cuestión con la que Gamerro, a través de esta novela, está lidiando: la posibilidad de un accionar exterior, de trayectos emancipadores respecto a los imaginarios del neoliberalismo y la "pos-historia", de líneas de fuga del atrapamiento, la cooptación y la culpa. No obstante, creo que, al intentar formular los problemas y dar cuenta de su enorme complejidad, cumple con el papel que Jameson le asigna al arte, el de construir mapas cognitivos. Según este autor, el posmodernismo termina con la distancia crítica en que se basaba la acción cultural contra el

${ }^{18} \mathrm{Y}$ a que Felipe se encuentra en una posición marginal: "En el dibujo [de Escher] hay uno que está afuera, acodado en la baranda al costado del edificio, contemplando sin curiosidad a los que suben y bajan. Me gustaría ser ése, ahí es donde me gustaría estar. Pero no sé cómo bajarme; le debe pasar a la mayoría, por eso terminamos saltando" (414). 
capitalismo, lo que hace que incluso las formas contraculturales hayan sido absorbidas por el sistema. En este "momento de verdad del posmodernismo", se hace necesaria una:

estética de la confección de mapas cognitivos. ... [que] tendría que conservar su objeto fundamental -el espacio mundial del capitalismo multinacional- y forzar al mismo tiempo una ruptura con él, mediante una nueva manera de representarlo... que nos permitiera recuperar nuestra capacidad de concebir nuestra situación como sujetos individuales y colectivos y nuestras posibilidades de acción y de lucha, hoy neutralizadas por nuestra doble confusión espacial y temporal (119).

En Las Islas se dibujan algunos de estos mapas que nos permitan ubicarnos en los espacios y desplazarnos por ellos, saliendo de las telas de araña y de los laberintos.

\section{Referencias}

Agamben, G. (2000). Lo que queda de Auschwitz. El archivo y el testigo. Homo Sacer III. Valencia: Pre-textos.

Areco, Macarena. (2014). Confesiones subalternas: subjetivación, relato y culpa en tres novelas argentinas y chilenas de la posdictadura. Aisthesis, 56, 69-82.

Benjamin, W. (2008). El narrador. Introducción, traducción, notas e índices de Pablo Oyarzún. Santiago: Metales Pesados.

Castoriadis, C. (1999). Figuras de lo pensable. Madrid: Cátedra-Universitat de València.

. (2007 [1975]). La institución imaginaria de la sociedad. Buenos Aires: Tusquets.

Drucaroff, E. (2011). Los prisioneros de la torre. Política, relatos y jóvenes en la postdictadura. Buenos Aires: Emecé.

Gamerro, C. (2000). El sueño del señor juez. Buenos Aires: Sudamericana. . (2003). Harold Bloom y el canon literario. Madrid: Campo de Ideas. . (2006). El nacimiento de la literatura argentina y otros ensayos. Buenos Aires: Norma. . (2008). Ulises. Claves de lectura. Buenos Aires: Norma. (2010). Ficciones barrocas. Una lectura de Borges, Bioy Casares, Silvina Ocampo, Cortázar, Onetti y Felisberto Hernández. Buenos Aires: Eterna Cadencia. 
. (2011 [2002]). El secreto y las voces. Buenos Aires: Edhasa.

. (2011). Un yuppie en la columna del Che Guevara. Buenos Aires: Edhasa.

. (2012 [1998]). Las Islas. Buenos Aires: Edhasa.

. (2012 [2004]). La aventura de los bustos de Eva. Buenos Aires: Edhasa. . (2013 [2005]). El libro de los afectos raros. Buenos Aires: Interzona.

Jameson, F. (1991 [1984]). El posmodernismo o la lógica cultural del capitalismo avanzado. Trad. José Luis Pardo. Barcelona: Paidós.

Laplanche, J. y Pontalis, J.-B. (1994). Diccionario de psicoanálisis. Barcelona: Labor. 